\title{
Adverse Reactions and Drug-Drug Interactions in the Management of Women with Postmenopausal Osteoporosis
}

\author{
René Rizzoli · Jean-Yves Reginster · Steven Boonen · Gérard Bréart • \\ Adolfo Diez-Perez • Dieter Felsenberg • Jean-Marc Kaufman · John A. Kanis • \\ Cyrus Cooper
}

Received: 28 November 2010/Accepted: 31 March 2011/Published online: 3 June 2011

(C) The Author(s) 2011. This article is published with open access at Springerlink.com

\begin{abstract}
The pharmacological management of disease should involve consideration of the balance between the beneficial effects of treatment on outcome and the probability of adverse effects. The aim of this review is to explore the risk of adverse drug reactions and drug-drug interactions with treatments for postmenopausal osteoporosis. We reviewed evidence for adverse reactions from regulatory documents, randomized controlled trials, pharmacovigilance surveys, and case series. Bisphosphonates are associated with gastrointestinal effects, musculoskeletal pain, and acute-phase reactions, as well as, very rarely, atrial fibrillation, atypical fracture, delayed fracture healing, osteonecrosis of the jaw, hypersensitivity reactions, and renal impairment. Cutaneous effects and osteonecrosis
\end{abstract}

Rizzoli has received lecture fees and/or on advisory boards for Merck Sharp and Dohme, Eli Lilly, Amgen, Wyeth, Novartis, Servier, Nycomed, Nestlé and Danone.

Reginster has received consulting and lecture fees, on paid advisory boards, and/or grant support from Servier, Novartis, Negma, Lilly, Wyeth, Amgen, GlaxoSmithKline, Roche, Merckle, Nycomed, NPS, Theramex, UCB, Merck Sharp and Dohme, Rottapharm, IBSA, Genevrier, Teijin, Teva, Ebewee Pharma, Zodiac, Analis, NovoNordisk, and Bristol Myers Squibb.

Boonen has received consulting and lecture fees, on paid advisory boards, and/or grant support from Amgen, Eli Lilly,

GlaxoSmithKline, Merck, Novartis, Ono, Roche, Sanofi-Aventis, Servier, and Warner Chilcott.

Bréart has received consulting fees and on paid advisory boards from Servier.

Diez-Perez has received consulting and lecture fees, on paid advisory boards, and/or grant support from Servier, Lilly, Amgen, GlaxoSmithKline, Merck Sharp and Dohme, and ViiV.

Felsenberg has received consulting and lecture fees, on paid advisory boards, and/or grant support from Amgen, Chugai, GE, Glaxo, Lilly, MSD, Novartis, Nycomed, Roche, Servier, Teva, Warner/Chilcott, and Wyeth/Pfizer.

Kaufman has received speaker and/or consultant fees and/or research support from Amgen, Daiichi-Sankyo, Glaxo SmithKline, Merck of the jaw are of concern for denosumab (both very rare), though there are no pharmacovigilance data for this agent yet. The selective estrogen receptor modulators are associated with hot flushes, leg cramps, and, very rarely, venous thromboembolism and stroke. Strontium ranelate has been linked to hypersensitivity reactions and venous thromboembolism (both very rare) and teriparatide with headache, nausea, dizziness, and limb pain. The solidity of the evidence base depends on the frequency of the reaction, and causality is not always easy to establish for the very rare adverse reactions. Drug-drug interactions are rare. Osteoporosis treatments are generally safe and well tolerated, though they are associated with a few very rare serious adverse reactions. While these are a cause for concern, the risk should be weighed against the benefits of

Sharp \& Dohme, Novartis, Nycomed, Servier, and Roche. Kanis has received consulting and lecture fees, on paid advisory boards, and/or grant support from Abiogen, Italy; Amgen, USA, Switzerland and Belgium; Bayer, Germany; Besins-Iscovesco, France; Biosintetica, Brazil; Boehringer Ingelheim, UK; Celtrix, USA; D3A, France; European Federation of Pharmaceutical Industry and Associations, (EFPIA) Brussels; Gador, Argentina; General Electric, USA; GSK, UK, USA; Hologic, Belgium and USA; Kissei, Japan; Leiras, Finland; Leo Pharma, Denmark; Lilly, USA, Canada, Japan, Australia and UK; Merck Research Labs, USA; Merlin Ventures, UK; MRL, China; Novartis, Switzerland and USA; Novo Nordisk, Denmark; Nycomed, Norway; Ono, UK and Japan; Organon, Holland; Parke-Davis, USA; Pfizer USA; Pharmexa, Denmark; Procter and Gamble, UK, USA; ProStrakan, UK; Roche, Germany, Australia, Switzerland, USA; Rotta Research, Italy; SanofiAventis, USA; Schering, Germany and Finland; Servier, France and UK; Shire, UK; Solvay, France and Germany; Strathmann, Germany; Tarsa Therapeutics, US; Tethys, USA; Teijin, Japan; Teva, Israel; UBS, Belgium; Unigene, USA; Warburg-Pincus, UK; WarnerLambert, USA; Wyeth, USA.

Cooper has received consulting fees from Alliance for Better Bone Health, Lilly, Merck Sharp and Dohme, GlaxoSmithKline, Roche, Novartis, Amgen, and Servier. 
treatment itself, i.e., the prevention of osteoporotic fracture.

Keywords Osteoporosis - Adverse drug reaction · Drug-drug interaction - Bisphosphonate - Denosumab . SERM - Strontium ranelate $\cdot$ Teriparatide

The management of osteoporosis is a major priority for public health. The disease affects about one-third of women over the age of 50 years, with a combined lifetime risk of hip, forearm, or vertebral fracture of around 50\%, on a par with the risk associated with cardiovascular disease [1]. The total direct costs in Europe were estimated at $€ 31.7$ billion in 2000 and are expected to nearly double by 2050 due to demographic changes in the population [2]. Effective and safe treatments are clearly essential to reduce this burden.

Fortunately, there is currently a wide range of osteoporosis treatments, which reduce the risk for vertebral fracture from 40 to $75 \%$ and, in some cases, nonvertebral fractures by about $20 \%$ and hip fractures up to $40 \%$ [3]. Like any disease, the pharmacological management of patients with osteoporosis should always involve consideration of the balance between the risk of adverse drug reactions and beneficial effects in terms of reduction in the risk of outcome. For osteoporosis, the outcome is vertebral and nonvertebral fracture, which is associated with significant levels of morbidity and disability and, in the case of vertebral and hip fracture, an increase in mortality. Treatment decisions should be made to attain the maximum reduction in risk of fracture with the minimum occurrence of adverse reactions. On the whole, osteoporosis treatments are remarkably well tolerated, though pharmacovigilance

\section{R. Rizzoli}

Division of Bone Disease, Department of Rehabilitation and Geriatrics, Geneva University Hospitals and

Faculty of Medicine, Geneva, Switzerland

\section{J.-Y. Reginster ( $\square)$}

Department of Public Health and Health Economics,

University of Liège, Liège, Belgium

e-mail: jyreginster@ulg.ac.be

\section{S. Boonen}

Leuven University Center for Metabolic Bone Disease

and Division of Geriatric Medicine, Katholieke

Universiteit Leuven, Leuven, Belgium

G. Bréart

INSERM U953, Hôpital Tenon, Paris, France

\section{A. Diez-Perez}

Department of Internal Medicine, Autonomous

University of Barcelona, Hospital del Mar, Barcelona, Spain and case studies have highlighted some rare serious adverse drug reactions, which deserve further investigation.

The Working Group of the European Society for Clinical and Economic Aspects of Osteoporosis and Osteoarthritis (ESCEO) has focused on adverse reactions and drug-drug interactions in the management of women with osteoporosis. This review was prepared following these discussions.

An adverse drug reaction is defined as an unintended harmful or unpleasant response to a medicinal product, which predicts hazard for future administration and warrants prevention or specific treatment, alteration of dosage, or discontinuation [4, 5]. In general medicine, adverse drug reactions are far more common than many physicians suppose [5]. In one prospective observational analysis of nearly 20,000 hospital admissions, $6.5 \%$ of patients had some form of adverse drug reaction, mainly due to aspirin, diuretics, warfarin, and nonsteroidal anti-inflammatory drugs [6]. The overall fatality in that analysis was $0.15 \%$. Despite this, many of the reactions are preventable through proper surveillance and education of physicians and patients.

In this review, we examine the evidence for adverse drug reactions with the following osteoporosis treatments: bisphosphonates (alendronate, risedronate, ibandronate, and zoledronic acid), denosumab, selective estrogen receptor modulators (SERMs, raloxifene and bazedoxifene), strontium ranelate, teriparatide, and $\mathrm{PTH}(1-84)$. We report the prevalence of side effects and adverse reactions according to the definitions used by the European Medicines Agency (EMA): common $(\geq 1 / 100,<1 / 10)$, uncommon $(\geq 1 / 1,000,<1 / 100)$, rare $(\geq 1 / 10,000,<1 / 1,000)$, and very rare $(<1 / 10,000)$.

Accurate interpretation of the risk of adverse reactions and drug-drug interactions is difficult due to the variety of

D. Felsenberg

Center of Muscle and Bone Research, Charité-University Medicine, Campus Benjamin Franklin, Berlin, Germany

J.-M. Kaufman

Department of Endocrinology and Unit for Osteoporosis and Metabolic Bone Diseases, Ghent University Hospital, Ghent, Belgium

J. A. Kanis

WHO Collaborating Centre for Metabolic Bone Diseases, University of Sheffield Medical School, Sheffield, UK

C. Cooper

MRC Epidemiology Resource Centre, University

of Southampton, Southampton, UK

C. Cooper

NIHR Musculoskeletal Biomedical Research Unit, Department of Musculoskeletal Science, University of Oxford, Oxford, UK 
sources of information that provide varying levels of evidence. The detection of an adverse reaction depends on the relative frequency of the event and the temporality, the mechanism of drug-induced toxicity, the number of patients exposed to the drug, and the methods used to detect the effect. There are three main sources of information in addition to regulatory documents: randomized controlled trials (RCTs), pharmacovigilance, and case reports [4]. Table 1 summarizes the source of evidence for the various adverse reactions with the osteoporosis treatments described herein and the duration of postapproval surveillance for each agent. Evidence from RCTs is restricted to the most common adverse reactions due to the small population size limited, at most, to a few thousand patients, as well as the relatively short observation times. On the other hand, rare side effects may not be detectable by RCTs and only become evident in pharmacovigilance surveys, which can cover hundreds of thousands of patients over many treatment years. Case reports also constitute an important source of information for the very rare events, though causality is not always easy to establish. It should be noted that the osteoporosis treatments that have been in clinical use for longer are more likely to have reported cases of rare adverse reactions than more recent arrivals to the therapeutic armamentarium.

\section{Adverse Reactions to Bisphosphonates}

Bisphosphonates are stable derivatives of inorganic pyrophosphate and potent antiresorptive agents. They are widely prescribed and highly effective at limiting bone loss in osteoporosis. There have been a number of recent reviews on the safety and tolerability of bisphosphonates in osteoporosis [7-14] as well as in oncology, where higher doses are applied alongside anticancer agents to prevent skeletal complications and relieve bone pain $[12,15]$.

All of the bisphosphonates discussed below have proven fracture efficacy in phase III trials [3]. The phase III trials for alendronate were carried out in the mid-1990s by the Fracture Intervention Trial (FIT) investigators, who demonstrated efficacy against vertebral and nonvertebral fracture, including hip [16, 17]. Alendronate was the first oral bisphosphonate and has 15 years of postapproval

Table 1 Source of evidence for adverse reactions to treatments in osteoporosis

\begin{tabular}{|c|c|c|c|c|}
\hline & \multicolumn{3}{|c|}{ Source of evidence } & \multirow[t]{2}{*}{ Duration of postapproval experience in 2010} \\
\hline & RCT & Pharmacovigilance & Case series & \\
\hline Bisphosphonates & & & & Alendronate, 15 years \\
\hline GI effects & $\boldsymbol{V}$ & $\checkmark$ & & Risedronate, 10 years \\
\hline Musculoskeletal pain & & $\checkmark$ & & Ibandronate (oral), 5 years \\
\hline Acute-phase reactions & $\checkmark$ & $\checkmark$ & & Ibandronate (IV), 4 years \\
\hline Atrial fibrillation & $\checkmark$ & $\checkmark$ & & Zoledronic acid, 3 years \\
\hline Atypical fracture/delayed fracture healing & & $\checkmark$ & $\checkmark$ & \\
\hline Osteonecrosis of the jaw & & $\checkmark$ & $\boldsymbol{V}$ & \\
\hline Hypersensitivity reactions & & $\boldsymbol{\sim}$ & $\boldsymbol{\nu}$ & \\
\hline Renal impairment & & $\checkmark$ & & \\
\hline Denosumab & & & & New agent \\
\hline Severe infection & $\boldsymbol{\nu}$ & & & \\
\hline Osteonecrosis of the jaw & & $\checkmark$ & $\boldsymbol{\nu}$ & \\
\hline Cancer & $\boldsymbol{\nu}$ & & & \\
\hline SERMs & & & & Raloxifene, 13 years \\
\hline Hot flushes & $\boldsymbol{V}$ & $\checkmark$ & & Bazedoxifene, new agent \\
\hline Leg cramps & $\boldsymbol{\nu}$ & $\checkmark$ & & Lasofoxifene, new agent \\
\hline Venous thromboembolism & $\boldsymbol{V}$ & $\checkmark$ & & \\
\hline Stroke & $\boldsymbol{V}$ & & & \\
\hline Endometrial effects & $\boldsymbol{V}$ & & & \\
\hline Strontium ranelate & & & & 8 years \\
\hline Venous thromboembolism & $\boldsymbol{\nu}$ & & & \\
\hline Hypersensitivity reactions & & $\checkmark$ & $\boldsymbol{V}$ & \\
\hline Teriparatide or PTH(1-84) & & & & 8 years \\
\hline Headache, nausea, dizziness, and limb pain & $\boldsymbol{V}$ & $\checkmark$ & & \\
\hline Osteosarcoma & & $\boldsymbol{\alpha}$ & $\boldsymbol{V}$ & \\
\hline
\end{tabular}


surveillance data [18]. Similar fracture efficacy was found for oral risedronate, in the Vertebral Efficacy with Risedronate Therapy (VERT) trials [19, 20] and the Hip Intervention Program (HIP) [21]. Risedronate was launched at the end of the 1990s, and there are now 10 years of postapproval surveillance for this agent [22]. Ibandronate has proven efficacy against vertebral fracture, as shown by the Oral Ibandronate Osteoporosis Vertebral Fracture Trial (BONE) [23]; but pivotal trials have not shown nonvertebral or hip fracture risk reduction with this agent. Ibandronate is prescribed both as a monthly oral formulation, with 5 years of postapproval surveillance, and as a trimonthly intravenous (IV) formulation, with 4 years of postapproval surveillance [24]. The most recently available bisphosphonate is zoledronic acid, for which there is evidence for the prevention of both vertebral and nonvertebral fractures, including those of the hip, from the Health Outcomes and Reduced Incidence with Zoledronic Acid Once Yearly (HORIZON) trial [25]. Zoledronic acid has been prescribed as a once-yearly IV formulation since 2007 [26], and there are 3 years of postapproval surveillance.

\section{Gastrointestinal Effects}

In their oral formulations, bisphosphonates may irritate the upper gastrointestinal (GI) mucosa since it is exposed to high concentrations at intake [27]. Proper adherence to administration instructions can reduce frequency of GI effects [27]. These include swallowing the drug with a large glass of water and remaining in the upright position for at least $30 \mathrm{~min}$ after intake (60 min for ibandronate).

Upper GI reactions are "common" with alendronate [18]. They are the most frequently reported adverse reactions with risedronate in drug monitoring, though the regulatory authorities do not cite an increased frequency of upper GI reactions with risedronate [22] and pooled analysis of RCTs found no evidence for an increase in risk compared with placebo [28]. Regarding ibandronate, GI tolerability was initially thought to be of concern with the high dosages necessary for monthly oral administration $(150 \mathrm{mg})$, but the investigators of the Monthly Oral Ibandronate in Ladies (MOBILE) trial found no apparent difference in GI adverse reactions between monthly and daily formulations [29], with rates comparable to alendronate (about 22\%). Upper GI effects are less frequent with weekly or monthly dosing than daily dosing for the same agent. Oral alendronate, risedronate, and ibandronate tablets also contain lactose, which causes abdominal discomfort in some patients but is rarely a severe problem.

The prevalence of esophageal reactions with alendronate is "common to rare" [18]. Two conflicting reports have appeared on the association of the long-term use of oral bisphosphonates (up to 5 years) and incidence of esophageal cancer [30, 31], both performed in the UK General Practice Research Database (GPRD). One of these reported a rate of $2 / 1,000$ over 5 years (against a background rate of 1/1,000) [30], while the other reported no association with esophageal or gastric cancer in users vs. nonusers [31]. Another analysis of over 15,000 patients identified in RCTs or postapproval surveys found rates of esophageal cancer similar to the background rates in the population [32], with an incidence of $<1 / 1,000,000$ patient-years of exposure. The Food and Drug Administration (FDA) currently recommends avoidance of oral bisphosphonates in patients with Barrett's esophagus, a precursor of esophageal cancer, and has called for further research on possible risk factors [33].

\section{Musculoskeletal Pain}

Chronic bone, joint, and muscle pain has been associated with intake of both oral and IV bisphosphonates [34] and was the subject of a warning from the FDA in 2008 [35]. The pathological basis for the reaction remains unclear, though there may be a link with elevated parathyroid hormone (PTH) levels [12]. Musculoskeletal pain is "common to rare" with alendronate [18] and "common" with zoledronic acid [26]. The FDA reports occurrences with alendronate, ibandronate, risedronate, and zoledronic acid, for which there was a (nonsignificant) difference vs. placebo [35]. Musculoskeletal pain can occur at any time during the course of treatment, though there may be some overlap with acute-phase reactions (see below). It can be difficult to manage, especially if severe $[7,8,10]$. Stopping treatment may give complete relief of symptoms, though there are cases of slow or incomplete resolution [34].

\section{Acute-Phase Reactions}

Acute-phase reactions have been reported with alendronate, ibandronate, and zoledronic acid $[9,10,12]$ and are characterized by low-grade fever, sometimes with rigors, and influenza-type symptoms, such as fatigue, malaise, headache, myalgia, arthralgia, and bone pain. They are attributed to altered activation and proliferation of $\gamma-\delta \mathrm{T}$ cells [36]. Onset may occur within 3 days of drug administration. The reaction is transient and generally resolves within 3 days [14].

These are rated as "rare" to "uncommon" by the EMA $[18,24,26]$; they appear to be more frequent with the IV bisphosphonates and are very rare following oral administration [37]. In the Dosing Intravenous Administration (DIVA) study, flu-like illness (33 symptoms) was reported to occur with an incidence of $4.9 \%$ with IV ibandronate vs. $1.1 \%$ for oral ibandronate [38]. They were also more common after the first injection of ibandronate than after subsequent administrations. Acute-phase symptoms have 
also been recorded after infusion of zoledronic acid (31.6\% after first infusion vs. $6.2 \%$ in the placebo group, less so after second infusion) [25, 26]. Acute-phase reactions are generally mild to moderate in intensity and are rarely the cause of withdrawal in RCTs. They can be treated symptomatically with paracetamol or other analgesics or antipyretics. The likelihood of experiencing this reaction can be reduced by administration of analgesics for a few days just after dosing [10].

\section{Atrial Fibrillation}

Concern over the possibility that bisphosphonates could induce atrial fibrillation $[39,40]$ followed the observation of a small but significant increase in this event with zoledronic acid in HORIZON when reported as serious adverse events (50 events [1.3\%] with zoledronic acid vs. 20 events [0.5\%] with placebo, $P<0.001$ ) [25]. The treatment-placebo difference was no longer significant when the events were analyzed separately as atrial fibrillation or atrial flutter events, sick sinus syndrome, or arrhythmias, adjudicated or not. Similar findings were reported for alendronate in a post hoc analysis of the FIT trial [41], in which there was a trend toward significance for atrial fibrillation (47 events [1.5\%] with alendronate vs. 31 events [1.0\%] with placebo, $P=0.07)$. Possible mechanisms for the modification of atrial conduction by bisphosphonates include intracellular electrolyte homeostasis and proinflammatory, profibrotic, and antiangiogenic effects [40].

Observational studies have failed to detect an increase in atrial fibrillation with any of the bisphosphonates [42, 43]. There is no RCT evidence that risedronate is associated with atrial fibrillation [44], and postapproval surveillance indicates an incidence of $<1 / 1,000,000$ patient-years with this agent. Similarly, there was no increase in atrial fibrillation in any of the ibandronate trials. Finally, a recent systematic review and meta-analysis concluded that, though there are data linking bisphosphonate use to atrial fibrillation, the exact nature of the risk remains unclear because of the heterogeneity of the evidence and the lack of information on some of the agents [45]. In 2008, the FDA concluded that no change in treatment should be made with respect to atrial fibrillation [34].

\section{Atypical Subtrochanteric Fracture and Delayed \\ Fracture Healing}

The occurrence of atypical subtrochanteric fracture and delayed fracture healing with bisphosphonates has been the subject of a separate ESCEO Working Group meeting and review [46] and a report from a Task Force of the American Society for Bone and Mineral Research [47] and will be discussed only briefly here. Case reports draw attention to an association between subtrochanteric fractures and exposure to bisphosphonates, possibly related to long-term suppression of bone turnover [48], as demonstrated by the absence of tetracycline labeling [49]. Cortical bone appears to be the most affected, and patients with thick cortices may be more susceptible to an effect on fracture [48]. Further supporting results for the deterioration of bone structural quality with long-term bisphosphonate use were presented at the annual meeting of the American Academy of Orthopedic Surgeons in March 2010 [50, 51].

There is no RCT evidence for an increase in the risk of subtrochanteric fractures with any of the bisphosphonates [52]. There have been case reports of atypical fracture or delayed fracture healing with long-term alendronate $[18,53-55]$, even though there are no quantitative differences in bone microarchitecture with alendronate [56]. There is also evidence from case series with risedronate $[54,55]$, for which postapproval surveys indicate $<1 /$ 100,000 patient-years [57]. There are three cases of atypical subtrochanteric fracture with ibandronate [55], which occurred after 4 months to 1 year of ibandronate treatment preceded by 3-10 years of alendronate. There was no delayed fracture healing in the HORIZON trial $(3.2 \%$ with zoledronic acid vs. $2.7 \%$ with placebo, nonsignificant) [58].

The evidence for a link between increased atypical subtrochanteric fracture or delayed fracture healing and long-term bisphosphonate therapy [46] generally comes from retrospective case series with small numbers of patients involved. The low frequency of atypical subtrochanteric fractures and the difficulties surrounding the definition of patients at risk considerably complicate the attribution of causality [52]. Current hypotheses include a possible association of reduced bone turnover induced by the bisphosphonate and other risk factors, such as younger age at initiation or concomitant therapy with corticosteroids, proton pump inhibitors, or other antiresorptive treatments [47, 52]. Further studies, including prospective controlled studies, meta-analyses, and nested case-control studies, are necessary to determine the role of other concomitant risk factors [46].

\section{Osteonecrosis of the Jaw}

Osteonecrosis of the jaw is the appearance of exposed bone in the mandible, maxilla, or both that persists for at least 8 weeks in the absence of radiotherapy or jaw metastases. The condition is known to affect patients receiving IV bisphosphonate for metastatic disease [59]. Patients in oncology generally receive much larger doses than those with osteoporosis. Assessment of causality is very difficult, though there is a possible role of inflammation and infection $[60,61]$. 
The association of osteonecrosis of the jaw and bisphosphonate treatment for osteoporosis has already been the subject of a separate ESCEO Working Group paper [61]. Osteonecrosis of the jaw is very rare with oral bisphosphonates in the management of osteoporosis, and current estimates of incidence stand at around 1/38,000 patient-years of treatment [61-64]. Data from the GPRD and The Health Improvement Network (THIN) suggest that the annual incidence of all osteonecrosis is 2 to $3 / 100,000$, independently of bisphosphonate use [65]. The lower doses of bisphosphonates used in osteoporosis, in comparison with oncology, appear to be safe [66].

There have been no cases of osteonecrosis of the jaw reported with risedronate in RCTs, and the postapproval reporting rate is $<2 / 100,000$ patient-years, with 434 reports in which $30-35 \%$ of patients had taken the drug for $<1$ year (S. Boonen, personal communication). There were two cases of osteonecrosis of the jaw in the HORIZON trial, one in the zoledronic acid group and one in the placebo group [67]. The rate in the zoledronic acid-treated osteoporotic population is currently estimated at 0.9 / 100,000 patient-years of treatment. For ibandronate, the rate is $0.9 / 1,000,000$ patients exposed in osteoporosis vs. 2.3/100,000 patients exposed in oncology (R. Schimmer, personal communication).

Some strategies for prevention of osteonecrosis of the jaw have been proposed in oncology, including good oral hygiene, completion of dental work prior to initiation of treatment, and discontinuation of treatment for 3 months in the event that a dental procedure is necessary [61, 66]. Any intervention at the jaw in patients using bisphosphonates for osteoporosis should include antibiotic therapy for 3 weeks. Management of osteonecrosis of the jaw involves treatment of secondary infections, analgesia, and surgical removal of necrotic debris [63, 68].

\section{Hypersensitivity Reactions}

Cutaneous adverse reactions are the subject of a separate ESCEO report [69]. Cases of Stevens-Johnson syndrome and toxic epidermal necrolysis have been reported for all the bisphosphonates [13, 69], though these remain very rare $(<1 / 10,000$ patients). These reactions have a strong temporality and appear within 5-10 days of initiation of treatment. Unsurprisingly for a very rare reaction, there are more case reports for the agents that have been in clinical use for the longest. The prognosis is good if the reaction is recognized early and managed appropriately [69].

\section{Renal Safety}

The use of IV bisphosphonates in oncology has been associated with rare cases of deterioration of renal function due to the high doses administered over a short period of time [70]. Analysis of the HORIZON trial demonstrated the renal safety of IV zoledronic acid in osteoporosis [70], with no long-term change in renal function in terms of creatinine clearance. There were transient rises in serum creatinine in $1.8 \%$ of treated patients vs. $0.8 \%$ of the placebo group, but all cases were completely resolved. The FDA reports 24 cases in postapproval (i.e., very rare), while the EMA describes renal impairment as "uncommon" and advises precaution in at-risk patients [26]. Further support for the good renal safety of IV bisphosphonates in osteoporosis comes from a pooled analysis of the renal tolerability of ibandronate in four RCTs. No relevant differences in parameters of renal toxicity were found between the IV formulation and oral formulations (incidence of increase in serum creatinine from baseline of $\geq 0.5 \mathrm{mg} / \mathrm{dl}$ of about $0.4 \%$ ). Regardless of dose, creatinine clearance remained at baseline levels and was comparable to placebo [71].

\section{Adverse Reactions to Denosumab}

The efficacy of denosumab in the prevention of fracture in postmenopausal osteoporosis was demonstrated vs. placebo in the Fracture Reduction Evaluation of Denosumab in Osteoporosis Every 6 Months (FREEDOM) trial [72]. Denosumab is a fully human monoclonal antibody against the RANK ligand and a potent inhibitor of osteoclastmediated bone resorption. Denosumab was approved for clinical use very recently, so the only evidence for safety and adverse reactions in osteoporosis is based on phase III studies [72, 73] and regulatory documents [74]. Case reports with the agent are rare, and there are not yet any pharmacovigilance data.

There were no significant differences between denosumab and placebo in terms of the total incidence of adverse events in FREEDOM or in the Denosumab Hormone Ablation Bone Loss Trial (HALT) [72, 73]. In FREEDOM, adverse events occurring with an incidence of $2 \%$ or greater and a significant difference from placebo $(P \leq 0.05)$ were eczema and flatulence [72]. Serious adverse events occurring with an incidence of $0.1 \%$ or greater and a significant difference from placebo $(P \leq 0.01)$ included cellulitis and concussion.

\section{Infections}

Data from RCTs indicate a higher rate of serious infection with denosumab than placebo $(4.4 \%$ vs. $3.6 \%$, respectively) [74-76], including infection of the skin, the ear, the GI tract, and the urinary tract. These can be related to bacteria or unspecified pathogens. This is biologically 
plausible since RANKL is expressed on activated T and B lymphocytes, which, in the lymph nodes, are responsible for recognition of foreign antigens [77]. RANKL inhibition with denosumab may therefore play some role in arresting these processes, though further research is necessary. Infection of the urinary tract is rated as "common" by the FDA [74].

The cutaneous effects observed in the denosumab RCTs (eczema and cellulitis) were generally localized infections in the lower extremities and often occurred in patients with risk factors such as skin wounds or peripheral vascular and venous stasis disorders. The clinical course generally consisted of full recovery with no recurrence, though cutaneous effects were linked to one death in FREEDOM (one case of fatal cellulitis). These cutaneous effects do not appear to be a local reaction to injection. It is too early to determine causality, though an increase in cutaneous effects with denosumab vs. placebo remained when data from FREEDOM and HALT were combined (D. Felsenberg, personal communication). The rate can be estimated as "very rare" $(<1 / 10,000$ patients). The risk should be monitored.

\section{Osteonecrosis of the Jaw}

Given the observations with the bisphosphonates, it might be expected that a potent antiresorptive agent such as denosumab could also pose a potential risk for osteonecrosis of the jaw [78]. There were no cases of osteonecrosis of the jaw in the phase III studies of denosumab in osteoporosis. There is one case report of osteonecrosis of the jaw in a male patient receiving denosumab in a trial in oncology [79]. Moreover, the reaction has been reported in 34 subjects receiving denosumab for the management of metastatic disease [80]. The rate can be estimated at around $2 / 100$, but the true risk is unknown and should be monitored. It should be noted that in this comparative trial the rate of occurrence of osteonecrosis of the jaw was $1.4 \%$ in zoledronic acid-treated patients.

\section{Cancer}

Preregistration RCTs with denosumab indicate slightly higher rates of malignancy in osteoporotic women $(4.0 \%$ with denosumab vs. $3.3 \%$ with placebo) [74], principally cancer of the pancreas, the GI and reproductive tracts, and the breast. Breast cancer was the most common adverse event that led to discontinuation in clinical trials $(0.5 \%$ denosumab vs. $0.3 \%$ placebo). The mechanisms underlying these processes remain unclear, particularly in the absence of an appropriate animal model as denosumab is not active in rodents. The rate can be estimated as "very rare," though further monitoring is necessary. A postmarketing survey of more than 4,500 women has been launched in postmenopausal women receiving the agent for up to 10 years.

\section{Adverse Reactions to SERMs}

SERMs partially mimic the effect of estrogens on bone and the cardiovascular system and have estrogen antagonist properties in the endometrium and breast. The efficacy of the SERM raloxifene in the prevention of osteoporotic fracture was extensively studied in the Multiple Outcomes of Raloxifene Evaluation (MORE) [81] and Continuing Outcomes Relevant to Evista (CORE) [82]. Its effects on breast cancer and other outcomes were explored in the Study of Tamoxifen and Raloxifene (STAR) [83] and the Raloxifene Use for the Heart (RUTH) trial [84, 85]. Raloxifene was launched in the 1990s and has 13 years of postapproval surveillance [86].

There are two newcomers to the class. The SERMs bazedoxifene and lasofoxifene were registered by the EMA in 2009, but only basedoxifene is currently available for clinical use [87-89]. The efficacy of bazedoxifene at preventing osteoporotic fracture over 3 years has been investigated vs. placebo [90], and its endometrial, ovarian, and breast safety profiles have been evaluated in an RCT in postmenopausal osteoporotic women, also over 3 years [91]. Lasofoxifene has been studied in the 5-year Postmenopausal Evaluation and Risk Reduction with Lasofoxifene (PEARL) trial, which reported efficacy at increasing bone mineral density and reducing radiographic vertebral fracture $[92,93]$.

\section{Hot Flushes and Leg Cramps}

The most common adverse reactions of the SERMs are linked to their vasomotor effects. The incidence of hot flushes and leg cramps was significantly increased in the raloxifene trials $[94,95]$. The mechanisms behind these phenomena are believed to be related to the competing effect of the SERM on the relevant estrogen receptor. In a pooled analysis of nearly 900 women participating in phase III trials, the relative risk of hot flushes has been estimated as 1.32 vs. placebo [94], with no apparent impact on the natural course of incident hot flushes. Regarding temporality, an 8-year analysis indicated that the increase in risk was greatest within the first 6 months of initiation of raloxifene [95]. While hot flushes and leg cramps were more common in those receiving raloxifene over 8 years than placebo, this was almost entirely explained by the increased incidence of hot flushes with raloxifene in the first 5 years. This observation may be due to the withdrawal of those with severe hot flushes or leg cramps from 
the trial or to an effect of aging of the population, which effectively reduces the risk for hot flushes. These effects are noted as "very common" for hot flushes and "common" for leg cramps for raloxifene by the EMA [86]. Similar rates of hot flushes and leg cramps are reported for bazedoxifene and lasofoxifene [87, 88, 90, 92, 96].

\section{Venous Thromboembolism}

Like hormone replacement therapy, treatment with SERMs is associated with an increased risk for venous thromboembolism, including deep vein thrombosis and pulmonary embolism [97]. The frequency of venous thromboembolism was increased in phase III trials with raloxifene, with a relative risk of about 1.7 vs. placebo in the combined analysis of MORE and CORE [85, 95, 98]. A large proportion of cases $(69 \%)$ had some contraindication to raloxifene (e.g., immobilization or hypercoagulability) [99]. The incidence was reduced in the long-term trial CORE [95], though this may have been linked to discontinuation due to these adverse reactions and because these events occurred at the beginning of treatment. The EMA notes this adverse reaction as "uncommon" with raloxifene [86].

There are fewer data for bazedoxifene and lasofoxifene. There was a higher incidence of deep vein thrombosis in the RCTs with bazedoxifene $(0.7 \%$ with bazedoxifene $20 \mathrm{mg} /$ day vs. $0.3 \%$ with placebo) [90, 96]. Venous thromboembolic events constituted an adjudicated end point in the PEARL trial [92], in which lasofoxifene more than doubled the relative risk, though the absolute risk was very small (2.9 venous thromboembolic events per 1,000 patient-years with lasofoxifene $0.5 \mathrm{mg} /$ day vs. 1.4 events with placebo and 0.7 pulmonary embolism events per 1,000 patient-years vs. 0.2 events with placebo) [92]. The EMA reports deep vein thrombosis as "uncommon" for both lasofoxifene and bazedoxifene [87, 88].

\section{Cardiovascular Events and Stroke}

An increase in fatal stroke with raloxifene was reported in RUTH (hazard ratio $=1.49,95 \%$ confidence interval $[\mathrm{CI}]$ $1.00-2.24$, with an absolute increase in risk of 0.7 per 1,000 patient-years) [85], though secondary analysis of the trial indicated that the risk of stroke varied according to smoking status [100]. Analysis of the MORE and CORE data set has demonstrated that raloxifene has no significant beneficial or harmful impact on cardiovascular events (i.e., coronary or cerebrovascular) [101]. This observation is also supported by the results of the RUTH study, in which participants were at higher cardiovascular risk [85] and in which there was no significant difference in total strokes or death from any cause. Moreover, there is evidence from animal experiments that high doses of raloxifene may be associated with some neuroprotective effects [102]. In the MORE study, higher doses of raloxifene $(120 \mathrm{mg} /$ day $)$ were associated with some improvement in the results of cognitive tests [103]. Regarding the other SERMS, there was a moderate, nonsignificant increase in fatal stroke with lasofoxifene in the PEARL study [92] and no difference from placebo for bazedoxifene in the 3-year phase III trial $[90,96]$. The EMA rates the incidence of stroke (arterial thromboembolic disorders) as "very rare" [86].

\section{Gynecological Safety}

Raloxifene and bazedoxifene have no impact on endometrial thickness [96, 104]. There was no significant difference in the incidence of uterine cancer, endometrial hyperplasia, ovarian cancer, or postmenopausal bleeding between raloxifene and placebo in the analysis of MORE and CORE [95]. There was a greater incidence of uterine polyps, though all of these were benign and not associated with endometrial cancer. Uterine polyps were also more common with lasofoxifene than placebo in the PEARL study [92]. The rate of these events can be estimated as "very rare" $(<1 / 10,000$ patients).

\section{Adverse Reactions to Strontium Ranelate}

Strontium ranelate is an orally active agent which decreases bone resorption and increases bone formation markers, with a net result of improved microarchitecture [105]. The efficacy of strontium ranelate in the prevention of vertebral and nonvertebral fractures, including hip fracture in a subgroup at risk of hip fracture, has been demonstrated in postmenopausal osteoporotic women over 3 years in the Spinal Osteoporosis Therapeutic intervention (SOTI) [106] and up to 5 years in the Treatment of Peripheral Osteoporosis (TROPOS) trial [107]. There were no significant safety issues in either of these phase III trials. Strontium ranelate has been in clinical use since 2004 and has 6 years of postapproval surveillance.

\section{Venous Thromboembolism}

There was no increase in venous thromboembolism with strontium ranelate in the SOTI and TROPOS populations. However, when the two trial populations were pooled, the annual incidence of venous thromboembolism over 5 years was $0.9 \%$ with strontium ranelate vs. $0.6 \%$ with placebo (relative risk $=1.4,95 \%$ CI 1.0-2.0) [108]. While these rates of venous thromboembolism are similar to those in the age-matched general population [109-111], they required further investigation. A retrospective study in the GPRD database identified 11,546 untreated osteoporotic 
women, 20,084 osteoporotic women treated with alendronate, 2,408 osteoporotic women treated with strontium ranelate, and 115,009 nonosteoporotic women [112]. The risk for venous thromboembolism in this population-based sample was significantly increased in the untreated osteoporotic patients compared with their nonosteoporotic counterparts (hazard ratio $=1.43,95 \%$ CI $1.10-1.86 ; \quad P=0.007$, age-adjusted model). The authors attributed this increase in risk to the reduced mobility associated with osteoporosis. There was no difference between the rates of venous thromboembolism in untreated and treated osteoporotic patients, whatever their treatment (strontium ranelate or alendronate). Similar findings have been reported from two other observational studies, so the postmarketing data are reassuring $[113,114]$.

\section{Hypersensitivity Reactions}

Strontium ranelate has been associated with rare cases of the hypersensitivity drug reaction with eosinophilia and systemic symptoms (DRESS). The incidence of this adverse reaction is extremely low, estimated at 1/54,000 patient-years of treatment. This has been discussed in a recent ESCEO Working Group review [69]. Early recognition and proper management by stopping the agent are mandatory and improve prognosis.

\section{Adverse Reactions to Teriparatide or PTH(1-84)}

Teriparatide, the 1-34 N-terminal fragment of human PTH, has bone-forming properties [115]. It has been demonstrated to effectively reduce vertebral and nonvertebral fractures over 21 months in postmenopausal osteoporotic women [116]. Its use is limited to 24 months of treatment $[115,117]$. Teriparatide has been in clinical use since 2002 and has 8 years of postapproval surveillance. PTH(1-84) was approved for vertebral fracture prevention in 2006 and is available in some countries [118].

\section{Nervous System Disorders}

In the placebo-controlled trials of teriparatide and PTH(1-84), there were a number of minor adverse reactions, including headache, nausea, and dizziness, which are rated as "common" to "very common" by the EMA. Teriparatide also appears to be associated with an increase in limb pain [117], which is noted as "very common" by the EMA. In a study exploring the efficacy of combination teriparatide and raloxifene in osteoporosis, muscle spasm was the only adverse reaction reported to be related to treatment with teriparatide [119].

\section{Osteosarcoma}

There were no cases of osteosarcoma in the RCTs with teriparatide or PTH(1-84), though teriparatide has been reported to induce osteosarcoma in experimental animals $[120,121]$. There is one case report of osteosarcoma with teriparatide in a 70-year-old postmenopausal woman with a complex medical history [122]. This reaction is rated as extremely rare (1/100,000 patients) and should be considered against the background incidence in the general population, which is around $0.4 / 100,000$ per year in a population aged over 60 years [8, 122]. However, this has led to an FDA warning [123], including a statement that patients who have skeletal metastases, Paget disease, or open epiphyses should not be prescribed teriparatide.

\section{Drug-Drug Interactions in Osteoporosis}

Drug-drug interactions are rare in the management of osteoporosis and discussed only briefly here. Coadministration of oral bisphosphonates and calcium or acid-suppressant medication, or indeed any other oral medications containing divalent cations, is known to interfere with absorption of the bisphosphonate. Calcium supplementation should therefore be distanced from bisphosphonate intake. An apparent increase in the risk of fracture has been reported in individuals receiving acid-suppressant medication (proton pump inhibitors) but not with histamine $\mathrm{H}_{2}$ receptor antagonists [124]. This increase in risk remained in patients receiving acid-suppressant medication in combination with bisphosphonates vs. bisphosphonate alone. Given the nature of the risk, this issue requires further exploration.

Caution is also recommended with oral bisphosphonates and the concomitant use of agents that irritate the gastric mucosa (e.g., nonsteroidal anti-inflammatory drugs) due to the GI effects of the bisphosphonate. There does not appear to be cause for concern over drug-drug interactions for ibandronate [125]. Renal damage due to bisphosphonates could be exacerbated by nonsteroidal anti-inflammatory agents, aminoglycoside antibiotics, antiretroviral therapies, or diuretics [126, 127]. Thus, care should be taken to administer IV bisphosphonates to only fully hydrated patients. Regarding zoledronic acid, renal function should be monitored and drugs affecting cardiac arrhythmias should be used with caution. One case of transient elevated liver enzymes has been reported with zoledronic acid and ibuprofen. There are not yet any reported drug-drug interactions of concern for denosumab.

Cholestyramine and colestipol may also affect the absorption and enterohepatic recycling of raloxifene. Levothyroxine may decrease the absorption of the drug. 
There are few drug-drug interactions with strontium ranelate. There are possible interactions with quinolones, tetracycline antibiotics, and aluminum and magnesium hydroxides; and the administration of strontium ranelate should be separated from intake of dietary calcium by $2 \mathrm{~h}$. There is a possible interaction between teriparatide and other treatments that affect serum calcium, though no interaction has been detected with digoxin or thiazides.

\section{Discussion and Conclusion}

This review indicates that the most serious adverse reactions are very rare in the management of postmenopausal osteoporosis and that the osteoporosis treatments are generally free of serious drug-drug interactions. We have reviewed the most commonly used osteoporosis treatments in Europe as well as new agents in the field.
Causality is notoriously difficult to attribute for rare adverse drug reactions, e.g., osteonecrosis of the jaw and atypical subtrochanteric fracture $[4,5,128]$. Such decisions are also fraught with interrater differences in opinion since studies repeatedly show low agreement between experts regarding causality when they assess the same case reports [129]. Causality can only be definitively established if a certain number of criteria are met: (1) a plausible temporality in relation to administration; (2) a reasonable mechanism in view of the agent concerned; (3) a frequency that differs from the background rate of the event in the population; and (4) evidence from dechallenge and rechallenge (though this is clearly not an option in the case of life-threatening events). One example of the difficulties in establishing causality in osteoporosis is osteosarcoma with teriparatide, which appears to occur at rates similar to the background rate in the elderly population. While the best evidence for causality should ideally come from RCT

Table 2 Adverse reactions to treatments in osteoporosis

\begin{tabular}{|c|c|c|c|c|c|c|}
\hline & Prevalence & $\begin{array}{l}\text { Strength of } \\
\text { association }\end{array}$ & $\begin{array}{l}\text { Consistency } \\
\text { of association }\end{array}$ & $\begin{array}{l}\text { Dose- } \\
\text { response }\end{array}$ & Temporality & $\begin{array}{l}\text { Biological } \\
\text { plausibility }\end{array}$ \\
\hline \multicolumn{7}{|l|}{ Bisphosphonates } \\
\hline GI effects (oral formulations) & Common $(\geq 1 / 100)$ & ++ & ++ & + & + & + \\
\hline Musculoskeletal pain & Common $(\geq 1 / 100)$ & + & + & - & + & - \\
\hline Acute-phase reactions (IV formulations) & Common $(\geq 1 / 100)$ & ++ & ++ & + & + & + \\
\hline Atrial fibrillation & Very rare $(<1 / 10,000)$ & - & - & - & - & - \\
\hline Atypical fracture/delayed fracture healing & Very rare $(<1 / 10,000)$ & \pm & - & - & + & + \\
\hline Osteonecrosis of the jaw & Very rare $(<1 / 10,000)$ & - & - & - & - & + \\
\hline Hypersensitivity reactions & Very rare $(<1 / 10,000)$ & + & + & - & + & - \\
\hline Renal impairment & Very rare $(<1 / 10,000)$ & + & + & + & + & + \\
\hline \multicolumn{7}{|l|}{ Denosumab } \\
\hline Severe infection & Common $(\geq 1 / 100)$ & + & + & - & + & + \\
\hline Osteonecrosis of the jaw & Very rare $(<1 / 10,000)$ & - & - & - & - & + \\
\hline Cancer & Very rare $(<1 / 10,000)$ & - & - & - & - & - \\
\hline \multicolumn{7}{|l|}{ SERMs } \\
\hline Hot flushes & Very common $(>1 / 10)$ & ++ & ++ & + & + & + \\
\hline Leg cramps & Common $(\geq 1 / 100)$ & + & + & + & + & + \\
\hline Venous thromboembolism & $\begin{array}{l}\text { Uncommon }(\geq 1 / 1,000 \\
\text { to }<1 / 100)\end{array}$ & + & + & + & + & + \\
\hline Stroke & Very rare $(<1 / 10,000)$ & - & - & - & - & - \\
\hline Endometrial effects & Very rare $(<1 / 10,000)$ & + & + & + & + & + \\
\hline \multicolumn{7}{|l|}{ Strontium ranelate } \\
\hline Venous thromboembolism & Very rare $(<1 / 10,000)$ & + & - & - & - & - \\
\hline Hypersensitivity reactions & Very rare $(<1 / 10,000)$ & + & - & - & + & - \\
\hline \multicolumn{7}{|l|}{ Teriparatide or PTH(1-84) } \\
\hline $\begin{array}{l}\text { Headache, nausea, dizziness, } \\
\text { and limb pain }\end{array}$ & Common $(\geq 1 / 100)$ & + & + & + & + & + \\
\hline Osteosarcoma & Very rare $(<1 / 10,000)$ & - & - & - & - & \pm \\
\hline
\end{tabular}

++ strong evidence, + evidence, \pm mixed evidence, - no evidence 
data, this is virtually impossible for the rare events. For instance, there were only two reports of bisphosphonaterelated osteonecrosis of the jaw in RCTs, and one of those was in the placebo group.

The monitoring of risk and pharmacovigilance are therefore central features of any drug safety program. Improvements in pharmacovigilance should increase the knowledge of adverse reactions via intensive monitoring and database studies (such as those performed on venous thromboembolism and osteonecrosis of the jaw in the GPRD) and the use of algorithms for assessing the probability of an adverse reaction [130, 131]. Indeed, postapproval studies are necessary to make objective decisions regarding rare serious adverse reactions. As shown in Table 1, the rare adverse reactions are generally only reported in pharmacovigilance or as case series and often only appear with widespread clinical use of the agent concerned. Regarding case reports, the evidence base is less solid, partly because they may be biased by opinions of the reporter and partly because they do not necessarily give an accurate assessment of the risk due to underreporting or selective reporting [130].

Table 2 synthesizes and classifies the adverse drug reactions to osteoporosis treatments in terms of their prevalence, the strength and consistency of the association, dose-response and temporality, and biological plausibility as reported in this review. For the sake of simplicity, we have assumed class effects for the bisphosphonates and SERMs. The more common adverse reactions, e.g., GI effects with oral bisphosphonates and hot flushes with SERMs, are well documented and generally associated with higher values for strength and consistency of the association, dose-response, temporality, and biological plausibility. On the other hand, the rarer adverse reactions have no strong evidence on any of these points and yet are serious enough to require further monitoring. For example, osteonecrosis of the jaw and atypical subtrochanteric fracture have been clearly documented as issues of concern by regulatory authorities for the antiresorptive agents; however, the low incidence of the reactions and the limited capacity to explore it using conventional evidence criteria, such as RCTs, make it difficult to be categorical about the association.

A good management strategy should always weigh the risk of adverse reactions against the benefits of treatment, i.e., the prevention of osteoporotic fracture. We should recall that all the osteoporosis treatments covered in this review have proven efficacy at reducing vertebral fracture in women with postmenopausal osteoporosis, and some have evidence for nonvertebral and hip fractures. It should be noted that perhaps the biggest risk associated with adverse drug reactions might be that a patient's fear of an adverse reaction would prevent him or her from taking the osteoporosis medication in the appropriate manner, thereby increasing the risk of fracture. In this context, great care should be applied in the provision of information on adverse drug reactions to patients, particularly in light of studies that show that patients significantly overestimate the likelihood of an adverse reaction occurring [132, 133].

In conclusion, osteoporosis treatments are generally safe and well tolerated. They are associated with a few very rare serious adverse reactions, such as osteonecrosis of the jaw, atypical fracture, and atrial fibrillation. While these are clearly a cause for concern and should be the subject of further investigations and monitoring, the risk of these rare events, which occur at a prevalence of less than 1 in 10,000 patients, should be weighed against the benefits of treatment itself, i.e., the prevention of osteoporotic fracture and associated morbidity.

Acknowledgments We thank the following people for their valuable input to this review: P. Borenstein, D. Cahall, A. Chines, S. Korte, B. Mitlak, R. Schimmer, and M. Spratka. S. Novack is deeply acknowledged for editorial assistance.

Open Access This article is distributed under the terms of the Creative Commons Attribution Noncommercial License which permits any noncommercial use, distribution, and reproduction in any medium, provided the original author(s) and source are credited.

\section{References}

1. International Osteoporosis Foundation (2009) Facts and statistics about osteoporosis and its implications. www.iofbonehealth. org/facts-and-statistics.html. Cited 10 Aug 2009

2. Melton LJ III, Gabriel SE, Crowson CS et al (2003) Costequivalence of different osteoporotic fractures. Osteoporos Int 14:383-388

3. Sambrook P, Cooper C (2006) Osteoporosis. Lancet 367:2010 2018

4. Edwards IR, Aronson JK (2000) Adverse drug reactions: definitions, diagnosis, and management. Lancet 356:1255-1259

5. Katz MD (2010) Evaluation of adverse drug reactions. In: Mushlin SB, Greene HL II (eds) Decision making in medicine. An algorithmic approach, 3rd edn. Mosby Elsevier, Philadelphia, pp 698-699

6. Pirmohamed M, James S, Meakin S et al (2004) Adverse drug reactions as cause of admission to hospital: prospective analysis of 18,820 patients. BMJ 329:15-19

7. Kennel KA, Drake MT (2009) Adverse effects of bisphosphonates: implications for osteoporosis management. Mayo Clin Proc 84:632-637

8. Solomon DH, Rekedal L, Cadarette SM (2009) Osteoporosis treatments and adverse events. Curr Opin Rheumatol 21:363368

9. Strampel W, Emkey R, Civitelli R (2007) Safety considerations with bisphosphonates for the treatment of osteoporosis. Drug Saf 30:755-763

10. Recker RR, Lewiecki EM, Miller PD et al (2009) Safety of bisphosphonates in the treatment of osteoporosis. Am J Med 122:S22-S32 
11. Watts NB, Diab DL (2010) Long-term use of bisphosphonates in osteoporosis. J Clin Endocrinol Metab 95:1555-1565

12. Papapetrou PD (2009) Bisphosphonate-associated adverse events. Hormones (Athens) 8:96-110

13. Abrahamsen B (2010) Adverse effects of bisphosphonates. Calcif Tissue Int 86:421-435

14. Rizzoli R (2011) Bisphosphonates for post-menopausal osteoporosis: are they all the same? QJM 104:281-300

15. Coleman RE (2008) Risks and benefits of bisphosphonates. Br J Cancer 98:1736-1740

16. Black DM, Cummings SR, Karpf DB et al (1996) Randomised trial of effect of alendronate on risk of fracture in women with existing vertebral fractures. Fracture Intervention Trial Research Group. Lancet 348:1535-1541

17. Cummings SR, Black DM, Thompson DE et al (1998) Effect of alendronate on risk of fracture in women with low bone density but without vertebral fractures: results from the Fracture Intervention Trial. JAMA 280:2077-2082

18. European Medicines Agency (2009) Alendronate. Summary of product characteristics. http://www.emea.europa.eu. Cited 19 Jan 2010

19. Harris ST, Watts NB, Genant HK et al (1999) Effects of risedronate treatment on vertebral and nonvertebral fractures in women with postmenopausal osteoporosis: a randomized controlled trial. Vertebral Efficacy with Risedronate Therapy (VERT) Study Group. JAMA 282:1344-1352

20. Reginster J, Minne HW, Sorensen $\mathrm{OH}$ et al (2000) Randomized trial of the effects of risedronate on vertebral fractures in women with established postmenopausal osteoporosis. Vertebral Efficacy with Risedronate Therapy (VERT) Study Group. Osteoporos Int 11:83-91

21. McClung MR, Geusens P, Miller PD et al (2001) Effect of risedronate on the risk of hip fracture in elderly women. Hip Intervention Program Study Group. N Engl J Med 344:333-340

22. Food and Drug Administration (2002) Risedronate. Description. http://www.fda.gov. Cited 11 Feb 2010

23. Chesnut CH, Skag A, Christiansen C et al (2004) Effects of oral ibandronate administered daily or intermittently on fracture risk in postmenopausal osteoporosis. J Bone Miner Res 19:12411249

24. European Medicines Agency (2007) Ibandronate. Summary of product characteristics. http://www.emea.europa.eu. Cited 11 Feb 2010

25. Black DM, Delmas PD, Eastell R et al (2007) Once-yearly zoledronic acid for treatment of postmenopausal osteoporosis. N Engl J Med 356:1809-1822

26. European Medicines Agency (2008) Zoledronic acid. Summary of product characteristics. http://www.emea.europa.eu. Cited 4 Jan 2010

27. Cryer B, Bauer DC (2002) Oral bisphosphonates and upper gastrointestinal tract problems: what is the evidence? Mayo Clin Proc 77:1031-1043

28. Taggart H, Bolognese MA, Lindsay R et al (2002) Upper gastrointestinal tract safety of risedronate: a pooled analysis of 9 clinical trials. Mayo Clin Proc 77:262-270

29. Reginster JY, Adami S, Lakatos P et al (2006) Efficacy and tolerability of once-monthly oral ibandronate in postmenopausal osteoporosis: 2 year results from the MOBILE study. Ann Rheum Dis 65:654-661

30. Green J, Czanner G, Reeves G et al (2010) Oral bisphosphonates and risk of cancer of oesophagus, stomach, and colorectum: case-control analysis within a UK primary care cohort. BMJ 341:c4444

31. Cardwell CR, Abnet CC, Cantwell MM et al (2010) Exposure to oral bisphosphonates and risk of esophageal cancer. JAMA 304:657-663
32. Bilezikian J, Klemes A, Siris E (2009) Esophageal cancer reports coincident with risedronate use. J Bone Miner Res 24(Suppl 1): Abstract A09001305. J Bone Miner Res. http:// www.asbmr.org/Meetings/AnnualMeeting/Abstracts.aspx. Cited 12 Feb 2010

33. Wysowski DK (2009) Reports of esophageal cancer with oral bisphosphonate use. N Engl J Med 360:89-90

34. Food and Drug Administration (2008) Information on bisphosphonates. http://www.fda.gov/Drugs/DrugSafety/Default.htm. Cited 25 Feb 2010

35. Food and Drug Administration (2008) Severe pain with osteoporosis drugs. http://www.accessdata.fda.gov/scripts/cdrh/cfdocs/ psn/transcript.cfm?show=73. Cited 31 May 2010

36. Thompson K, Rogers MJ (2004) Statins prevent bisphosphonate-induced gamma, delta-T-cell proliferation and activation in vitro. J Bone Miner Res 19:278-288

37. Bock O, Boerst H, Thomasius FE et al (2007) Common musculoskeletal adverse effects of oral treatment with once weekly alendronate and risedronate in patients with osteoporosis and ways for their prevention. J Musculoskelet Neuronal Interact 7:144-148

38. Delmas PD, Adami S, Strugala C et al (2006) Intravenous ibandronate injections in postmenopausal women with osteoporosis: one-year results from the dosing intravenous administration study. Arthritis Rheum 54:1838-1846

39. Mak A, Cheung MW, Ho RC et al (2009) Bisphosphonates and atrial fibrillation: Bayesian meta-analyses of randomized controlled trials and observational studies. BMC Musculoskelet Disord 10:113

40. Pazianas M, Compston J, Huang CL (2010) Atrial fibrillation and bisphosphonate therapy. J Bone Miner Res 25:2-10

41. Cummings SR, Schwartz AV, Black DM (2007) Alendronate and atrial fibrillation. N Engl J Med 356:1895-1896

42. Heckbert SR, Li G, Cummings SR et al (2008) Use of alendronate and risk of incident atrial fibrillation in women. Arch Intern Med 168:826-831

43. Sorensen HT, Christensen S, Mehnert F et al (2008) Use of bisphosphonates among women and risk of atrial fibrillation and flutter: population based case-control study. BMJ 336:813816

44. Karam R, Camm J, McClung M (2007) Yearly zoledronic acid in postmenopausal osteoporosis. N Engl J Med 357:712-713

45. Loke YK, Jeevanantham V, Singh S (2009) Bisphosphonates and atrial fibrillation: systematic review and meta-analysis. Drug Saf 32:219-228

46. Rizzoli R, Akesson K, Bouxsein M et al (2011) Subtrochanteric fracture after long-term treatment with bisphosphonates. Osteoporos Int 22:373-390

47. Shane E, Burr D, Ebeling PR et al (2010) Atypical subtrochanteric and diaphyseal femoral fractures: report of a task force of the American Society for Bone and Mineral Research. J Bone Miner Res 25:2267-2294

48. Lenart BA, Neviaser AS, Lyman S et al (2009) Association of low-energy femoral fractures with prolonged bisphosphonate use: a case control study. Osteoporos Int 20:1353-1362

49. Odvina CV, Zerwekh JE, Rao DS et al (2005) Severely suppressed bone turnover: a potential complication of alendronate therapy. J Clin Endocrinol Metab 90:1294-1301

50. Ding A (2010) The structural effect of bisphosphonate treatment leading to atypical hip fractures. www3.aaos.org/eduction/ anmeet/anmt2010/podium/podium.cfm?Prevent=241. Cited 31 May 2010

51. Gladnick B, Donnely E, Lorich DG et al (2010) The effects of long-term bisphosphonate use on bone quality. www3.aaos.org/ eduction/anmeet/anmt2010/podium/podium.cfm?Prevent=339. Cited 31 May 2010 
52. Black DM, Kelly MP, Genant HK et al (2010) Bisphosphonates and fractures of the subtrochanteric or diaphyseal femur. N Engl J Med 362:1761-1771

53. Neviaser AS, Lane JM, Lenart BA et al (2008) Low-energy femoral shaft fractures associated with alendronate use. J Orthop Trauma 22:346-350

54. Odvina CV, Levy S, Rao S et al (2010) Unusual mid-shaft fractures during long-term bisphosphonate therapy. Clin Endocrinol (Oxf) 72:161-168

55. Ing-Lorenzini K, Desmeules J, Plachta O et al (2009) Lowenergy femoral fractures associated with the long-term use of bisphosphonates: a case series from a Swiss university hospital. Drug Saf 32:775-785

56. Recker R, Masarachia P, Santora A et al (2005) Trabecular bone microarchitecture after alendronate treatment of osteoporotic women. Curr Med Res Opin 21:185-194

57. Bilezikian J, Klemes A, Silverman S et al (2009) Subtrochanteric fracture reports coincident with risedronate use. J Bone Miner Res 24(Suppl 1): Abstract A09001333. J Bone Miner Res. http://www.asbmr.org/Meetings/AnnualMeeting/Abstracts.aspx. Cited 12 February 2010

58. Lyles K, Colon-Emeric CS, Magaziner JS et al (2007) Efficacy and safety of zoledronic acid $5 \mathrm{mg}$ in preventing fractures in men and women with prevalent hip fracture: The HORIZONRecurrent Fracture Trial. http://www.asbmr.org/Meetings/Past AnnualMeetings.aspx. Cited $25 \mathrm{Feb} 2010$

59. Migliorati CA, Siegel MA, Elting LS (2006) Bisphosphonateassociated osteonecrosis: a long-term complication of bisphosphonate treatment. Lancet Oncol 7:508-514

60. Lesclous P, Abi NS, Carrel JP et al (2009) Bisphosphonateassociated osteonecrosis of the jaw: a key role of inflammation? Bone 45:843-852

61. Rizzoli R, Burlet N, Cahall D et al (2008) Osteonecrosis of the jaw and bisphosphonate treatment for osteoporosis. Bone 42:841-847

62. Woo SB, Hellstein JW, Kalmar JR (2006) Narrative [corrected] review: bisphosphonates and osteonecrosis of the jaws. Ann Intern Med 144:753-761

63. Khosla S, Burr D, Cauley J et al (2007) Bisphosphonate-associated osteonecrosis of the jaw: report of a task force of the American Society for Bone and Mineral Research. J Bone Miner Res 22:1479-1491

64. Dunstan CR, Felsenberg D, Seibel MJ (2007) Therapy insight: the risks and benefits of bisphosphonates for the treatment of tumor-induced bone disease. Nat Clin Pract Oncol 4:42-55

65. Cooper C, Steinbuch M, Stevenson R et al (2010) The epidemiology of osteonecrosis: findings from the GPRD and THIN databases in the UK. Osteoporos Int 24:569-577

66. Khan A (2010) Osteonecrosis of the jaw and bisphosphonates. BMJ 340:c246

67. Grbic JT, Landesberg R, Lin SQ et al (2008) Incidence of osteonecrosis of the jaw in women with postmenopausal osteoporosis in the health outcomes and reduced incidence with zoledronic acid once yearly pivotal fracture trial. J Am Dent Assoc 139:32-40

68. Ruggiero SL, Dodson TB, Assael LA et al (2009) American Association of Oral and Maxillofacial Surgeons position paper on bisphosphonate-related osteonecrosis of the jaws-2009 update. J Oral Maxillofac Surg 67:2-12

69. Musette P, Brandi ML, Cacoub P et al (2010) Treatment of osteoporosis: recognizing and managing cutaneous adverse reactions and drug-induced hypersensitivity. Osteoporos Int 21:723-732

70. Boonen S, Sellmeyer DE, Lippuner K et al (2008) Renal safety of annual zoledronic acid infusions in osteoporotic postmenopausal women. Kidney Int 74:641-648

71. Miller PD, Leigh C, Ward P (2006) Renal tolerability of intravenous ibandronate allow administration by short injection.
Abstract FR10455. Ann Rheum Dis. http://www.eular.org/. Cited 26 Feb 2010

72. Cummings SR, San Martin J, Mac Clung MR et al (2009) Denosumab for prevention of fractures in postmenopausal women with osteoporosis. N Engl J Med 361:756-765

73. Smith MR, Egerdie B, Hernandez TN et al (2009) Denosumab in men receiving androgen-deprivation therapy for prostate cancer. N Engl J Med 361:745-755

74. Food and Drug Administration (2009) Background document for meeting of Advisory Committee for Reproductive Health Drugs (August 13, 2009) Denosumab. www.fda.gov. Cited 8 March 2010

75. Toulis A, Anastasilakis D (2010) Increased risk of serious infections in women with osteopenia or osteoporosis treated with denosumab. Osteoporos Int 21:1963-1964

76. Anastasilakis AD, Toulis KA, Goulis DG et al (2009) Efficacy and safety of denosumab in postmenopausal women with osteopenia or osteoporosis: a systematic review and a meta-analysis. Horm Metab Res 41:721-729

77. Ferrari-Lacraz S, Ferrari S (2011) Do RANKL inhibitors (denosumab) affect inflammation and immunity? Osteoporos Int 22:435-446

78. Kyrgidis A, Toulis KA (2011) Denosumab-related osteonecrosis of the jaws. Osteoporos Int 22:369-370

79. Taylor KH, Middlefell LS, Mizen KD (2010) Osteonecrosis of the jaws induced by anti-RANK ligand therapy. $\mathrm{Br} \mathrm{J}$ Oral Maxillofac Surg 48:221-223

80. Stopeck AT, Lipton A, Body JJ et al (2010) Denosumab compared with zoledronic acid for the treatment of bone metastases in patients with advanced breast cancer: a randomized, doubleblind study. J Clin Oncol 28:5132-5139

81. Ettinger B, Black DM, Mitlak BH et al (1999) Reduction of vertebral fracture risk in postmenopausal women with osteoporosis treated with raloxifene. Results from a 3-year randomized clinical trial. JAMA 282:637-645

82. Siris ES, Harris ST, Eastell R et al (2005) Skeletal effects of raloxifene after 8 years: results from the continuing outcomes relevant to Evista (CORE) study. J Bone Miner Res 20:1514-1524

83. Vogel VG, Costantino JP, Wickerham DL et al (2006) Effects of tamoxifen vs raloxifene on the risk of developing invasive breast cancer and other disease outcomes: the NSABP Study of Tamoxifen and Raloxifene (STAR) P-2 trial. JAMA 295:2727-2741

84. Mosca L, Barrett-Connor E, Wenger NK et al (2001) Design and methods of the Raloxifene Use for the Heart (RUTH) study. Am J Cardiol 88:392-395

85. Barrett-Connor E, Mosca L, Collins P et al (2006) Effects of raloxifene on cardiovascular events and breast cancer in postmenopausal women. N Engl J Med 355:125-137

86. European Medicines Agency (2008) Raloxifene. Summary of product characteristics. http://www.emea.europa.eu. Cited 4 Jan 2010

87. European Medicines Agency (2009) Lasofoxifene. Summary of product characteristics. http://www.emea.europa.eu. Cited 3 June 2010

88. European Medicines Agency (2009) Bazedoxifene. Summary of product characteristics. http://www.emea.europa.eu

89. Lewiecki EM (2009) Current and emerging pharmacologic therapies for the management of postmenopausal osteoporosis. J Womens Health 18:1615-1626

90. Silverman SL, Christiansen C, Genant HK et al (2008) Efficacy of bazedoxifene in reducing new vertebral fracture risk in postmenopausal women with osteoporosis: results from a 3-year, randomized, placebo-, and active-controlled clinical trial. J Bone Miner Res 23:1923-1934

91. Archer DF, Pinkerton JV, Utian WH et al (2009) Bazedoxifene, a selective estrogen receptor modulator: effects on the endometrium, 
ovaries, and breast from a randomized controlled trial in osteoporotic postmenopausal women. Menopause 16:1109-1115

92. Cummings SR, Ensrud K, Delmas PD et al (2010) Lasofoxifene in postmenopausal women with osteoporosis. N Engl J Med 362:686-696

93. Becker C (2010) Another selective estrogen-receptor modulator for osteoporosis. N Engl J Med 362:752-754

94. Cohen FJ, Lu Y (2000) Characterization of hot flashes reported by healthy postmenopausal women receiving raloxifene or placebo during osteoporosis prevention trials. Maturitas 34:65-73

95. Martino S, Disch D, Dowsett SA et al (2005) Safety assessment of raloxifene over eight years in a clinical trial setting. Curr Med Res Opin 21:1441-1452

96. De Villiers TJ, Kendler DL, Chines A et al (2009) Safety and tolerability of bazedoxifene in postmenopausal women with osteoporosis: results of a 5-year, randomized, placebo-controlled phase III trial. J Bone Miner Res 24(Suppl 1): Abstract A09002793. J Bone Miner Res. http://www.asbmr.org/ Meetings/AnnualMeeting/Abstracts.aspx. Cited 29 Dec 2009

97. Clemett D, Spencer CM (2000) Raloxifene: a review of its use in postmenopausal osteoporosis. Drugs 60:379-411

98. Grady D, Ettinger B, Moscarelli E et al (2004) Safety and adverse effects associated with raloxifene: multiple outcomes of raloxifene evaluation. Obstet Gynecol 104:837-844

99. Duvernoy CS, Kulkarni PM, Dowsett SA et al (2005) Vascular events in the Multiple Outcomes of Raloxifene Evaluation (MORE) trial: incidence, patient characteristics, and effect of raloxifene. Menopause 12:444-452

100. Mosca L, Grady D, Barrett-Connor E et al (2009) Effect of raloxifene on stroke and venous thromboembolism according to subgroups in postmenopausal women at increased risk of coronary heart disease. Stroke 40:147-155

101. Ensrud K, Genazzani AR, Geiger MJ et al (2006) Effect of raloxifene on cardiovascular adverse events in postmenopausal women with osteoporosis. Am J Cardiol 97:520-527

102. Dhandapani KM, Brann DW (2002) Protective effects of estrogen and selective estrogen receptor modulators in the brain. Biol Reprod 67:1379-1385

103. Yaffe K, Krueger K, Cummings SR et al (2005) Effect of raloxifene on prevention of dementia and cognitive impairment in older women: the Multiple Outcomes of Raloxifene Evaluation (MORE) randomized trial. Am J Psychiatry 162:683-690

104. Jolly EE, Bjarnason NH, Neven P et al (2003) Prevention of osteoporosis and uterine effects in postmenopausal women taking raloxifene for 5 years. Menopause 10:337-344

105. Marie PJ (2007) Strontium ranelate: new insights into its dual mode of action. Bone 40:S5-S8

106. Meunier PJ, Roux C, Seeman E et al (2004) The effects of strontium ranelate on the risk of vertebral fracture in women with postmenopausal osteoporosis. N Engl J Med 350:459-468

107. Reginster JY, Seeman E, De Vernejoul MC et al (2005) Strontium ranelate reduces the risk of nonvertebral fractures in postmenopausal women with osteoporosis: Treatment of Peripheral Osteoporosis (TROPOS) study. J Clin Endocrinol Metab 90:2816-2822

108. European Medicines Agency (2009) Strontium ranelate. Summary of product characteristics. http://www.emea.europa.eu. Cited 3 June 2010

109. Naess IA, Christiansen SC, Romundstad P et al (2007) Incidence and mortality of venous thrombosis: a population-based study. J Thromb Haemost 5:692-699

110. Oger E (2000) Incidence of venous thromboembolism: a community-based study in western France. EPI-GETBP Study Group. Groupe d'Etude de la Thrombose de Bretagne Occidentale. Thromb Haemost 83:657-660

111. Silverstein MD, Heit JA, Mohr DN et al (1998) Trends in the incidence of deep vein thrombosis and pulmonary embolism.
A 25-year population-based study. Arch Intern Med 158:585593

112. Breart G, Cooper C, Meyer O et al (2010) Osteoporosis and venous thromboembolism: a retrospective cohort study in the UK General Practice Research Database. Osteoporos Int 21:1181-1187

113. Breart G, Audran M, Brandi ML et al (2009) Good safety and persistence of strontium ranelate in a prospective observational cohort study. Osteoporos Int 20:S94

114. Perrio M, Wilton L, Shakir S (2008) Analysis of venous thromboembolism in the strontium ranelate prescription-event monitoring (PEM) cohort: interim results. Drug Saf 31:1

115. Blick SK, Dhillon S, Keam SJ (2008) Teriparatide: a review of its use in osteoporosis. Drugs 68:2709-2737

116. Neer RM, Arnaud CD, Zanchetta JR et al (2001) Effect of parathyroid hormone (1-34) on fractures and bone mineral density in postmenopausal women with osteoporosis. N Engl J Med 344:1434-1441

117. European Medicines Agency (2008) Teriparatide. Summary of product characteristics. http://www.emea.europa.eu. Cited 11 Feb 2009

118. Greenspan SL, Bone HG, Ettinger MP et al (2007) Effect of recombinant human parathyroid hormone (1-84) on vertebral fracture and bone mineral density in postmenopausal women with osteoporosis: a randomized trial. Ann Intern Med 146:326-339

119. Deal C, Omizo M, Schwartz EN et al (2005) Combination teriparatide and raloxifene therapy for postmenopausal osteoporosis: results from a 6-month double-blind placebo-controlled trial. J Bone Miner Res 20:1905-1911

120. Vahle JL, Sato M, Long GG et al (2002) Skeletal changes in rats given daily subcutaneous injections of recombinant human parathyroid hormone (1-34) for 2 years and relevance to human safety. Toxicol Pathol 30:312-321

121. Vahle JL, Long GG, Sandusky G et al (2004) Bone neoplasms in F344 rats given teriparatide $[\mathrm{rhPTH}(1-34)]$ are dependent on duration of treatment and dose. Toxicol Pathol 32:426-438

122. Harper KD, Krege JH, Marcus R et al (2007) Osteosarcoma and teriparatide? J Bone Miner Res 22:334

123. Food and Drug Administration (2008) FORTEO teriparatide (rDNA origin) injection. http://www.fda.gov/. Cited 9 Feb 2010

124. de Vries F, Cooper AL, Cockle SM et al (2009) Fracture risk in patients receiving acid-suppressant medication alone and in combination with bisphosphonates. Osteoporos Int 20:1989-1998

125. Bauss F, Kling L, Worth E et al (2010) Drug-drug interactions are unlikely with ibandronate. Abstract P374SU. Osteoporos Int 15(Suppl 1):S101

126. Perazella MA (2003) Drug-induced renal failure: update on new medications and unique mechanisms of nephrotoxicity. Am J Med Sci 325:349-362

127. Pannu N, Nadim MK (2008) An overview of drug-induced acute kidney injury. Crit Care Med 36:S216-S223

128. Naranjo CA, Busto U, Sellers EM (1982) Difficulties in assessing adverse drug reactions in clinical trials. Prog Neuropsychopharmacol Biol Psychiatry 6:651-657

129. Arimone Y, Miremont-Salame G, Haramburu F et al (2007) Inter-expert agreement of seven criteria in causality assessment of adverse drug reactions. Br J Clin Pharmacol 64:482-488

130. Harmark L, van Grootheest AC (2008) Pharmacovigilance: methods, recent developments and future perspectives. Eur $\mathrm{J}$ Clin Pharmacol 64:743-752

131. Doherty MJ (2009) Algorithms for assessing the probability of an adverse drug reaction. Respir Med 2:63-67

132. Berry DC, Knapp P, Raynor DK (2002) Provision of information about drug side-effects to patients. Lancet 359:853-854

133. Berry DC, Raynor DK, Knapp P et al (2003) Patients' understanding of risk associated with medication use: impact of European Commission guidelines and other risk scales. Drug Saf 26:1-11 